\title{
MINIATURE VENTILATORS WITH INTERRUPTED NON- REBREATHING CIRCLE SYSTEMS AND OTHER ANAESTHETIC CIRCUITS
}

\author{
GUY ForTin, M.D., and Victor F. Blanc, M.D.*
}

Modern miniature ventilators originated from South Africa in 1966 with Cohen's Minivent. ${ }^{1}$ This was followed by the Freeman Automatic Vent ${ }^{2}$ and the Carden Microvent. ${ }^{3}$ These ventilators have all been properly described and assessed.1,2

All three ventilators incorporate a magnetic valve consisting of a mobile magnet carrier which operates shuttlewise. In the expiratory mode the shuttle is attracted to a stationary magnet carrier. The shuttle is channelled to the inspiratory position with the rapidity of a toggle switch when the magnetic attraction is overcome by the pressure of gases in a distended rubber reservoir bag. This dual function reservoir bag provides pneumatic energy and delivers the anaesthetic mixture to the patient. When the pressure in the reservoir bag has fallen below the force of magnetic attraction, the shuttle rapidly toggles back to the expiratory position. The reservoir bag receives the anaesthetic mixture flowing at the desired minute volume. Provided that there are no leaks in the anaesthetic system, the entire minute volume will be delivered to the patient's lungs divided up into an adjustable number of tidal volumes. For a constant minute volume the tidal volume varies inversely with the respiratory rate. A preset minute volume which is greater than the measured expiratory volume on a Wright ventimeter ${ }^{4}$ signifies that a leak is present. By judicious adjustment of available controls on the respirators and the total gas flow, it is possible to supply precise volumetric ventilatory requirements to all patients regardless of age and possibly pulmonary compliance, provided that the counter-compliance of the power bag is compatible with the patient's total compliance.

In the past, the recommended anaesthetic systems involving the use of miniature ventilators have been of two types. One type involves the use of the respirator as an automatic non-rebreathing device linked directly to the endotracheal tube and relayed to the power source by a standard corrugated breathing tube (Fig. 1, Top System). The other system incorporates a non-rebreathing inflating valve connected directly to the endotracheal tube and linked to the miniature ventilator by a standard corrugated breathing tube. In this array, the ventilator is adjacent to the power bag (Fig. 1, Bottom System).

With the first system, we found that the cycling mechanism had a tendency to lock in the inspiratory position. We attribute this malfunction to the close proximity of the ventilator to the patient's airway. This sequential linear arrangement of pneumatic components leads to condensation of water vapour or deposition

'Le Service d'Anesthésie-Réanimation Notre-Dame, Hôpital Notre-Dame, Montréal. 


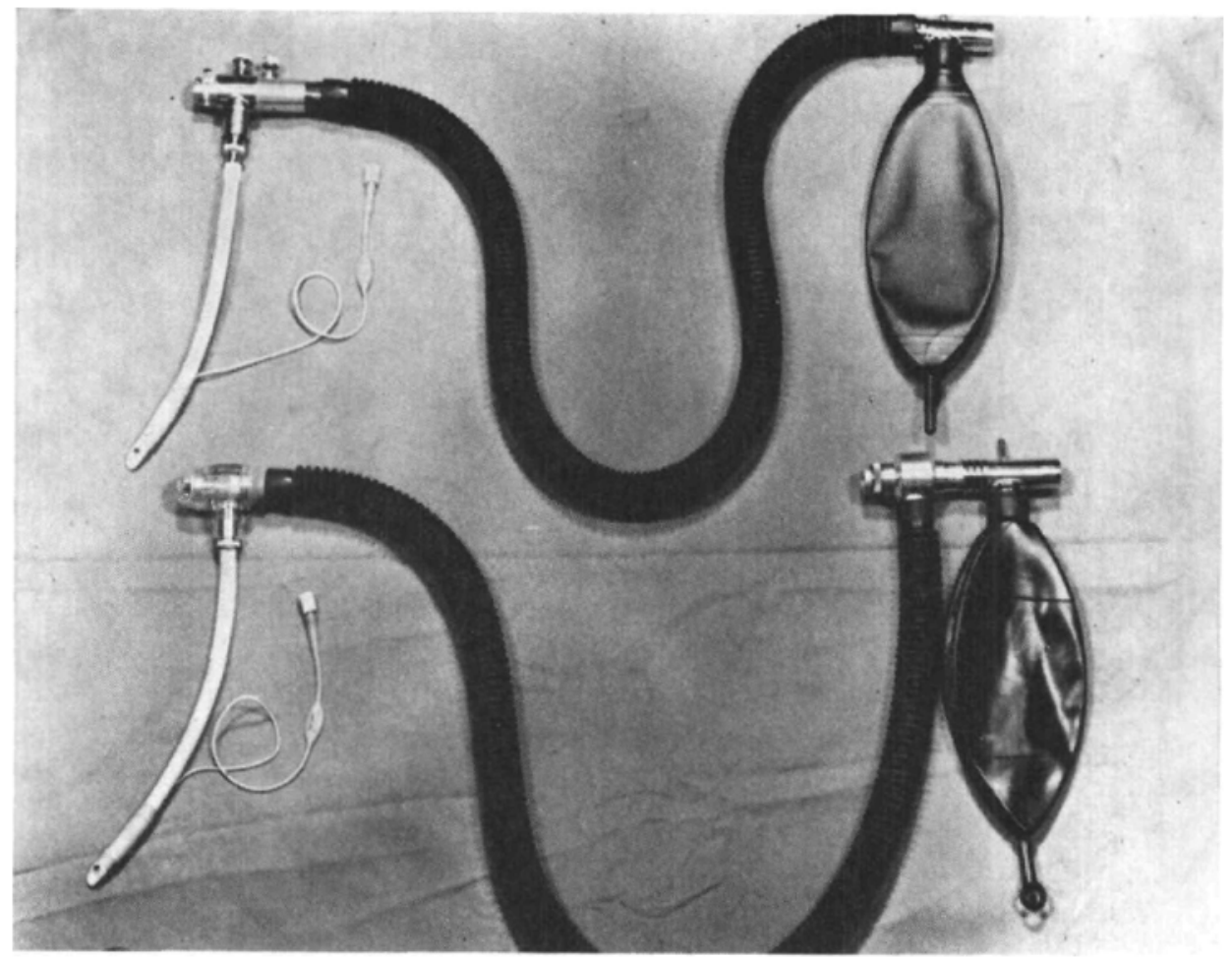

Figune 1. Two currently recommended linear systems for miniature ventilators, Microvent above; Minivent below. See text for explanation of sequential linear arrangement of components.

of secretions on the mobile magnet carrier and on the internal cylindrical wall of the respirator, although it is claimed that the Microvent is immune from malfunction attributable to condensation of water vapour. ${ }^{2,3,5}$

The other recommended system introduces the Ambu " $E$ " non-rebreathing inflating valve ${ }^{3,6}$ which in our opinion appears to interfere with the proper functioning of the respirator. This system which involves the linkage of two nonrebreathing devices, one of which is autonomically automatic, the other depending on the miniature ventilator for its semi-automaticity, may introduce undesirable conditions whereby the ventilator again may lock in the inspiratory position. When either system is used for surgery involving the cephalic extremity, whereby the anaesthetist is more or less isolated from the non-rebreathing inflating valve or ventilator, the occurrence of malfunction in these devices is not readily corrected because, under such circumstances, they are not readily accessible.

Figure 2 illustrates a system which we have found very convenient, readily accessible for adjustment and relatively safe. This system, referred to as the interrupted non-rebreathing circle, incorporates a unidirectional $\mathbf{y}$ valve connected to the endotracheal tube. This unidirectional valve is linked to the ventilator by means of two stiff-walled corrugated breathing tubes which are connected to a simple $\mathbf{Y}$ piece of suitable diameter without valves and directly fitted to the 


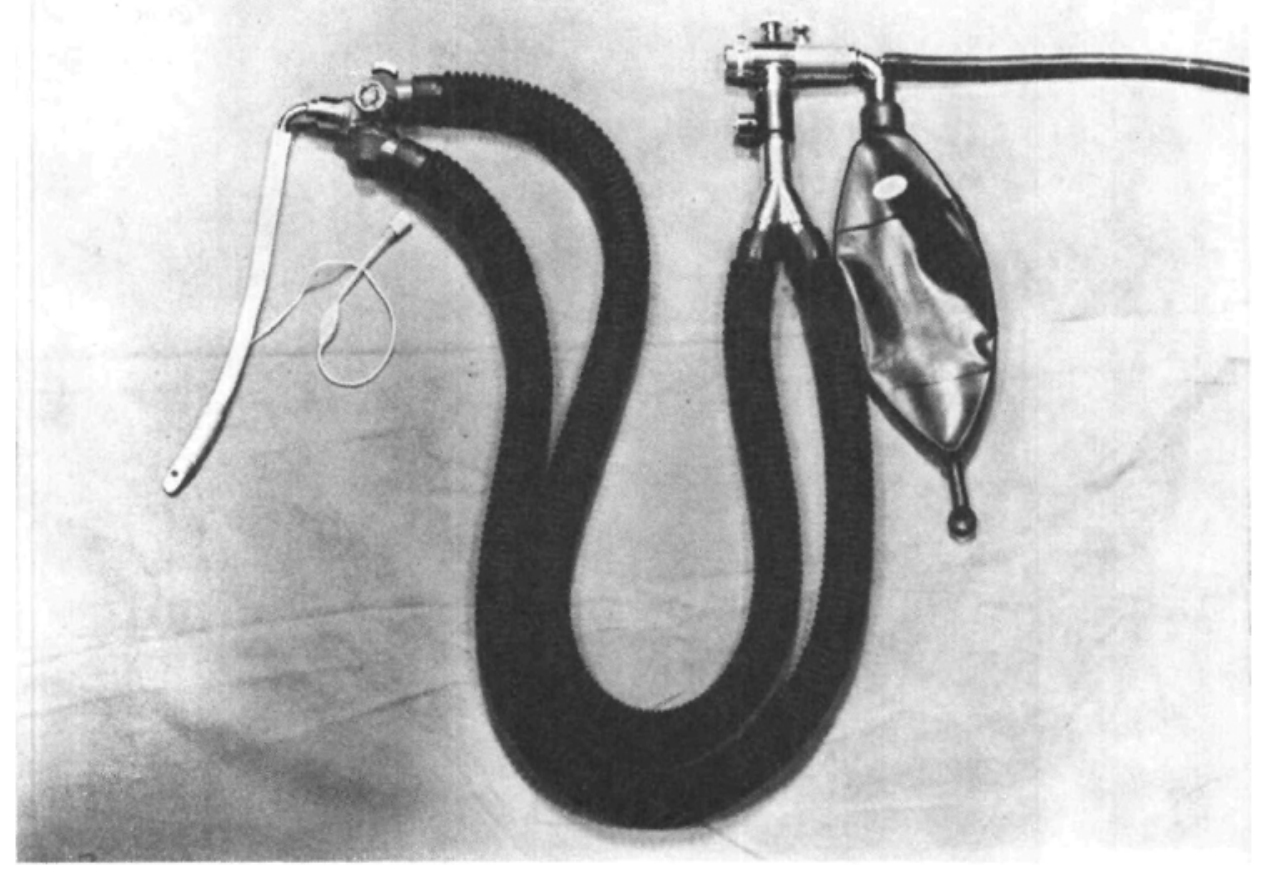

Frgune 2. Basic interrupted non-rebreathing circle circuit, $\mathbf{A} \mathbf{y}$ channel connected to the Microvent is joined to a unidirectional $\mathrm{Y}$ valve at the patient end by means of corrugated breathing tubes. Note the presence of a safety blow-off valve inserted between the Microvent and the $\mathrm{Y}$ channel.

ventilator. Thus in this circuit, the inspiratory and expiratory gases are vehicled through one common aperture, the expiratory function of which represents the "interruption" in the circuit.

Another version of this interrupted circle is represented in Figure 3. In this circuit, the absorber unit on the anaesthetic machine is used as a convenient, immediately available, "bracket" and $\mathrm{x}$ channel for the ventilator. Should the expired gases be directed through the absorber, the soda-lime will obviously become exhausted but since all the expired gases are eliminated into the ambient atmosphere through the common inspiratory-expiratory port, it follows that this system, which in effect is similar to the one illustrated in Figure 2, does not require the absorber to be included in the circuit.

In order to evaluate the efficiency of this non-rebreathing interrupted anaesthetic circle system mounted on an anaesthetic machine, arterial $\mathrm{CO}_{2}$ partial pressures $\left(\mathrm{Pa}_{\mathrm{CO}_{2}}\right)$ were determined in 12 patients. An initial $\mathrm{Pa}_{\mathrm{CO}_{2}}$ was obtained following a thirty-minute period of controlled ventilation with soda-lime included in the interrupted circle circuit. A second $\mathrm{Pa}_{\mathrm{CO}_{2}}$ determination was carried out following a subsequent thirty-minute period of controlled ventilation without soda-lime absorption of expired gases. 


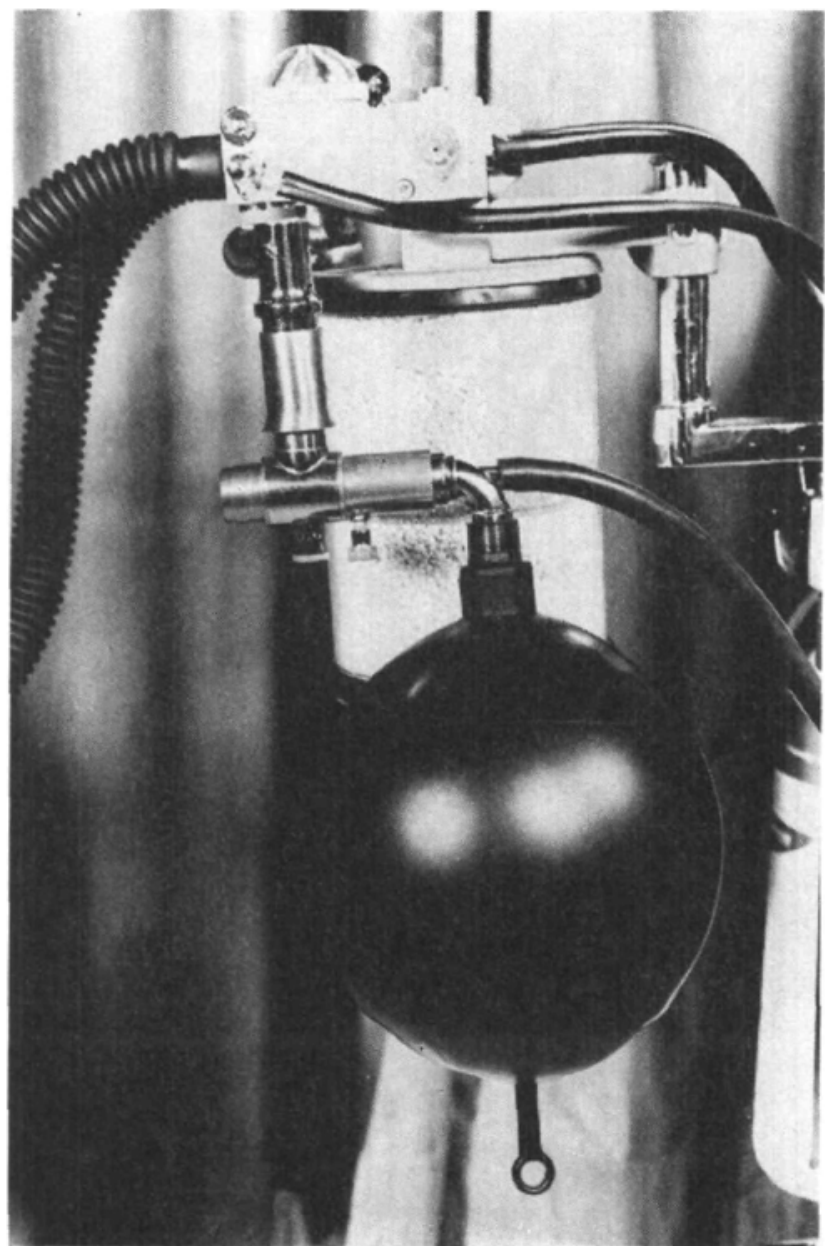

Figure 3. Interrupted non-rebreathing circle circuit mounted on an anaesthetic machine which functions as a "bracket" and $Y$ channel for the Microvent. In use, the soda-lime absorber is turned off:

Female and male patients were equally represented. Patients with no history of gross respiratory impairment were selected, and age ranged between 19 and 56 years. These patients were anaesthetised with oxygen nitrous-oxide mixture supplemented with either halothane or Innovar. Muscle relaxation and intentional respiratory paralysis were obtained by either d-tubocurarine or gallamine triethyodide. Surgical procedures during which blood gas studies were made included:

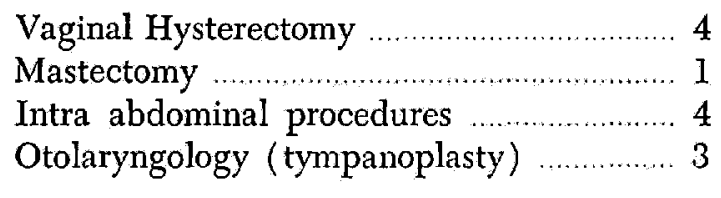

TOTAL: $\quad 12$ 


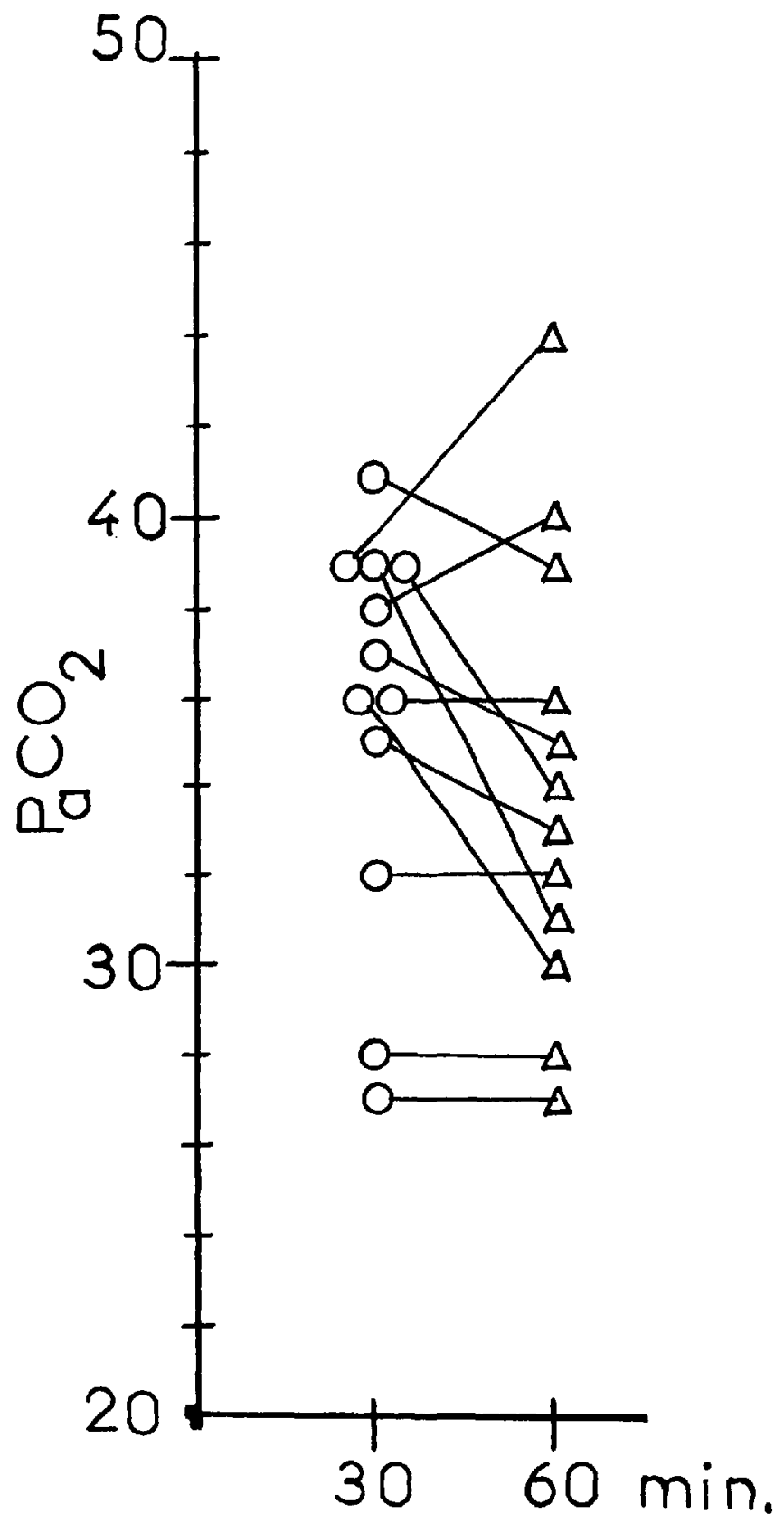

Ficure 4. Circles indicate arterial $\mathrm{P}_{\mathrm{CO}_{2}}$ in twelve patients following an interval of 30 minutes with soda-lime inserted in the interrupted circle system mounted on an anaesthetic machine. Triangles represent arterial $\mathrm{P}_{\mathrm{CO}_{2}}$ in the same patients following a subsequent interval of 30 minutes with soda-lime excluded. All readings were submitted to identical ventilatory parameters and the Minivent respirator utilized in all cases. See text for interpretation. 
Arterial blood samples were taken from the left radial artery in all patients and $\mathrm{Pa}_{\mathrm{CO}_{2}}$ determinations were carried out in all cases under identical conditions by the Astrup method.

As shown in Figure 4 the mean $\mathrm{PaCO}_{2}$ obtained with soda-lime in circuit (circles) was $35.38 \mathrm{~mm} \mathrm{Hg}$ whilst that obtained with soda-lime excluded (triangles) was lower at $34.08 \mathrm{~mm} \mathrm{Hg}$.

Upon further analysis, the graph shows no demonstrable variation in $\mathrm{Pa}_{\mathrm{CO}_{2}}$ in four patients following exclusion of soda-lime for a period of 30 minutes. Under identical conditions, six other patients exhibited a lower $\mathrm{Pa}_{\mathrm{CO}_{2}}$ following a thirtyminute period without soda-lime in circuit, the adjustment of controls on the ventilator as well as the flowmeter minute volume settings remaining constant in each individual case with and without soda-lime in circuit.

The $\mathrm{PaCO}_{2}$ was increased in only two patients following a thirty-minute ventilation period with the soda-lime canister excluded from the circuit. These two deviatons from the mean response may have been influenced by adrenaline infiltration of tissues performed for haemostatic purposes in one case and by a steep Trendelenburg position in the other.

The fall in $\mathrm{Pa}_{\mathrm{CO}_{2}}$ values observed in six of the twelve patients following exclusion of soda-lime is attributed to elimination of gas leaks and reduction in the circuit volume. Indeed, the Wright ventimeter revealed that closure of the soda-

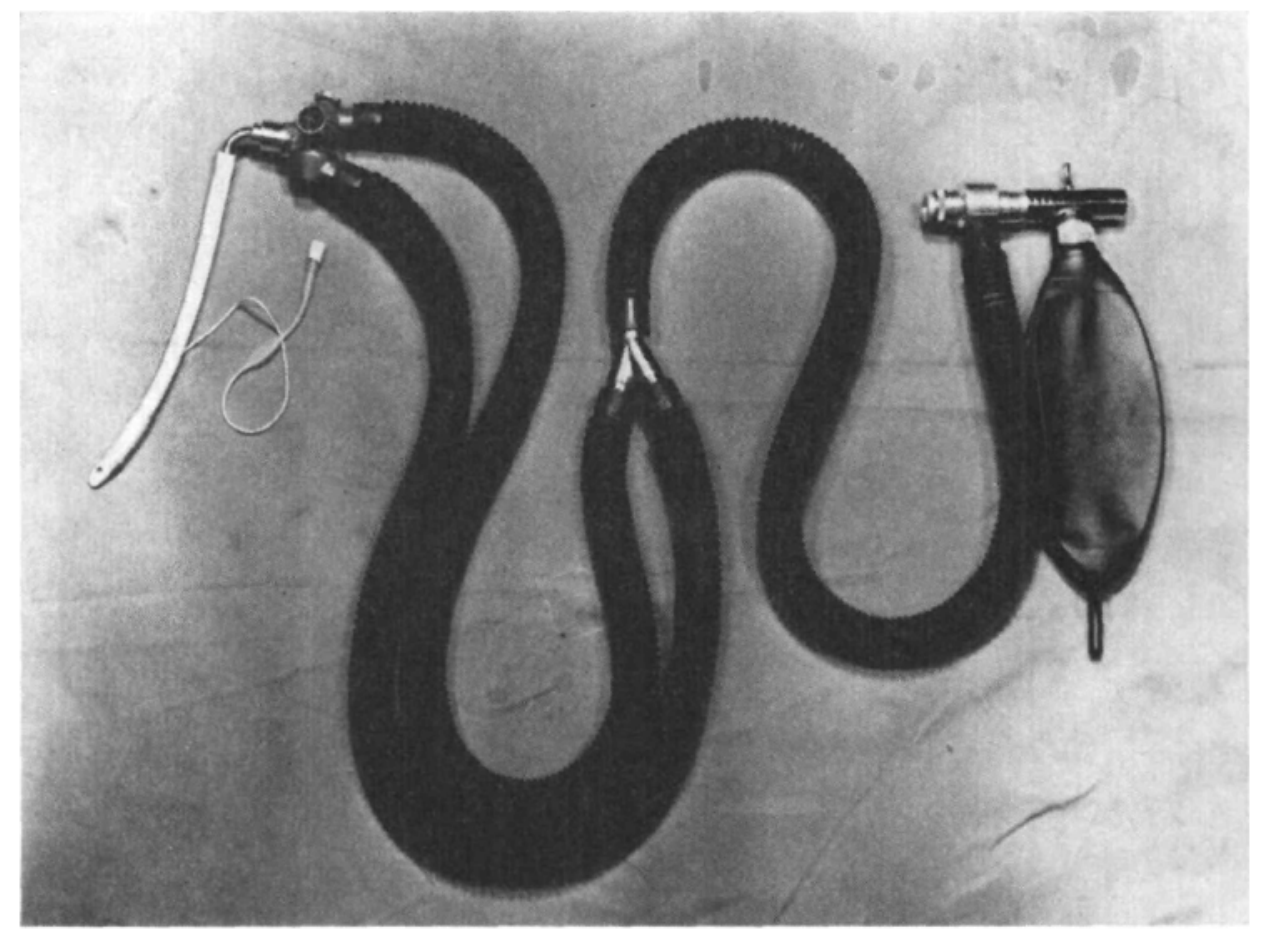

Ficure 5. A dangerous sequential arrangement is represented in this photograph. The dead mechanical space in the corrugated breathing tube joining the Minivent to the $y$ channel represents a potentially lethal circuit. 
lime canister results in a 50 to $80 \mathrm{ml}$ increase in the tidal volume when older machines (where leakage can be expected) are utilized as "brackets" for miniature ventilators.

It now becomes obvious that low cost miniature ventilators do not present the hazards of mechanical dead space when used as non-rebreathing units described herein.

It is imperative at this point that we issue a warning. In the interrupted circle non-rebreathing system, the ventilator should be connected as close as possible to the bag holder on the anaesthetic machine, or directly to the $\mathrm{Y}$ piece should this system be more convenient to use than the machine. Figure 5 illustrates an arrangement which we condemn vigorously for it incorporates a potential hazard. The long corrugated breathing tube connecting the ventilator to the interrupted breathing circle system represents mechanical dead space in which inspired and expired gases are vehicled in a to-and-fro manner. In a critical case should the volume of this corrugated tube be equivalent to the tidal volume delivered by the ventilator, the expiratory cycle would eliminate and totally replace the fresh gases by expired gases. A subsequent inspiratory cycle would vehicle expired gases toward the inspiratory tube of the circle. This situation obviously would soon result in asphyxia not to mention total absence of anaesthesia.

Although a clogged magnetic valve is a rare occurrence with the interrupted circle we have caused this malfunction to occur voluntarily by allowing some

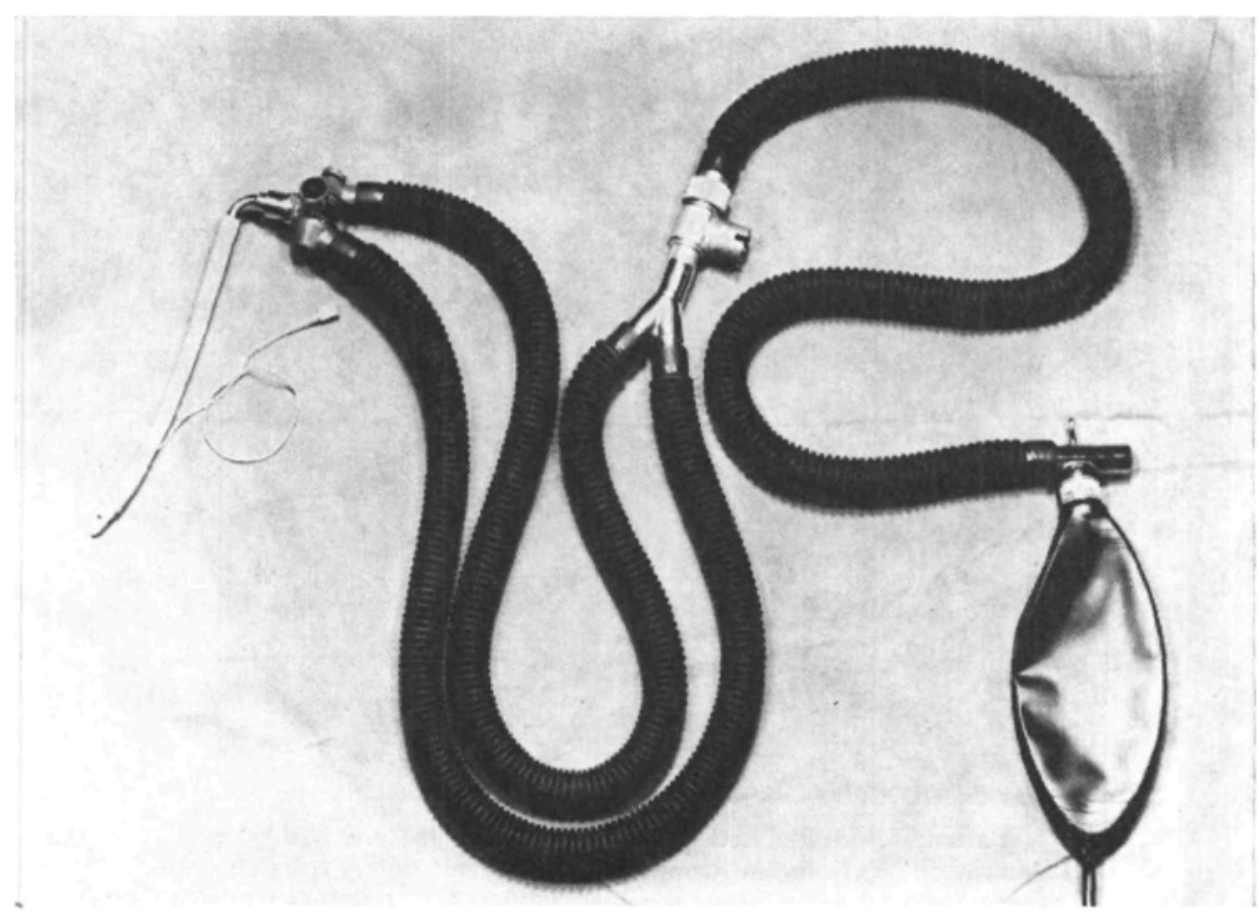

Figure 6. Recommended component sequence to attenuate the sound produced by the magnet valve in the ventilator. (Note position of Automatic Vent.) 
residual spontaneous respiratory activity in the patient. The opposing force created by an active expiration may be sufficient to hinder the free travel of the mobile magnet carrier. In order to avoid excessive build-up of intrapulmonary pressure from this cause, a safety valve $e^{3,5}$ which blows off at $35-40 \mathrm{~cm} \mathrm{H}_{2} \mathrm{O}$ is connected directly to the ventilator. If more convenient, it may also be connected to either the inspiratory or expiratory limbs of the circuit.

In the circuits shown in Figures 2 and 3, the close proximity of the power bag to the ventilator amplifies the clicking sound emitted by the magnet valve because the distended bag acts as a resonance chamber. The clicking sound, although not disagreeable, may be muffled by attaching the power bag at some distance from the respirator, as shown in Figure 6 where the power bag is connected to the respirator by a rigid corrugated breathing tube. In addition to their

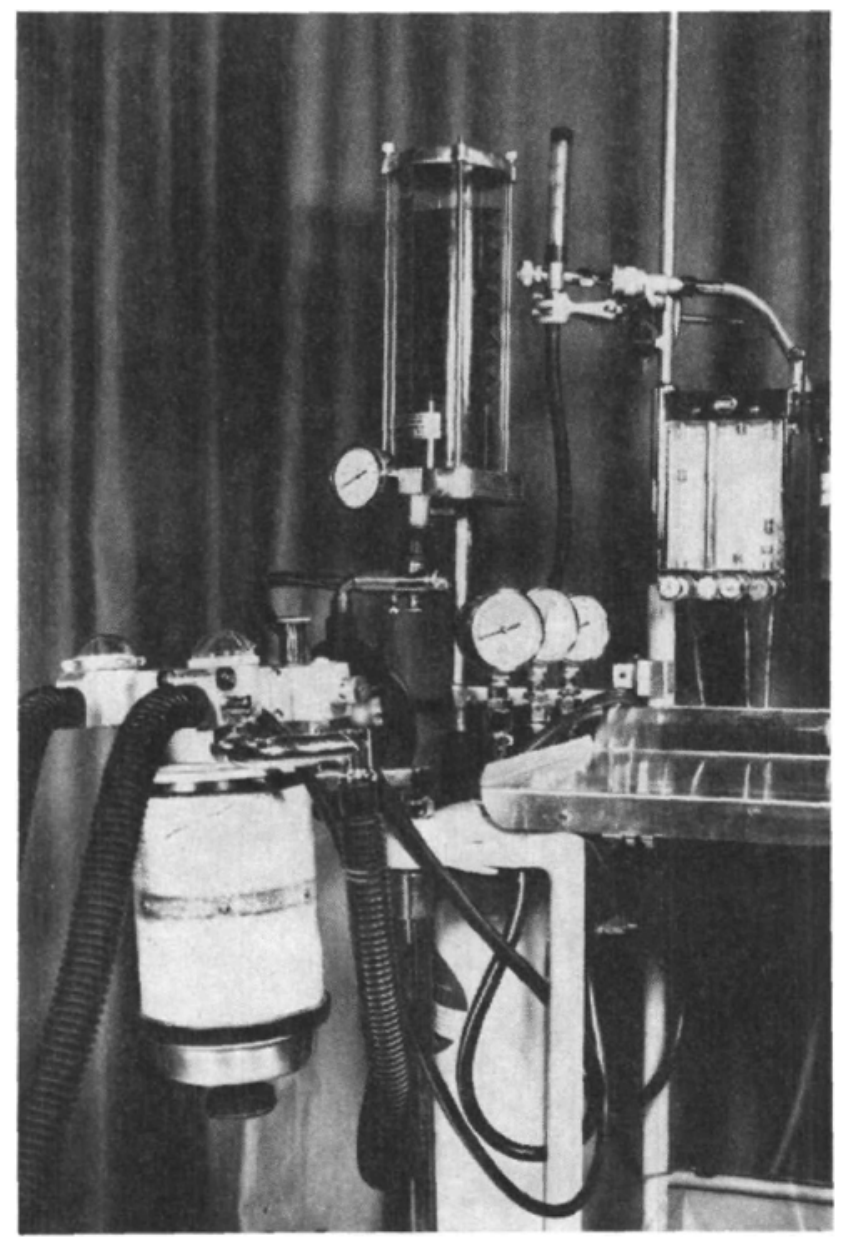

Ficure 7. Semi-closed partial-rebreathing system with the Microvent providing automaticity. This circuit deters from the less complex applications for which miniature ventilators were designed. 
compact design, sturdiness, and simplicity, the economic aspect of miniature ventilators deserves some consideration. Initial cost is very low as compared to larger units. ${ }^{2}$ When used with non-rebreathing interrupted circle systems in adults, a total minute volume flow of seven to ten liters using a mixture of oxygen, nitrous-oxide, and halothane is usually required to completely control respiration. This applies to almost all patients not receiving muscle relaxants thus providing an excellent criteria of the adequacy of ventilation. Under these circumstances, halothane concentration need not exceed 1.5 per cent. Although gas and volatile anaesthetic consumption may be higher in a non-rebreathing system, it must be recognized that not only do these flows provide the driving energy but also the anaesthesia. Whereas in a partial rebreathing semi-closed system, an accessory oxygen or air power source is necessary in addition to the anaesthetic mixture. Soda-lime is an additional expense.

In order to create a semi-closed partial-rebreathing system, the miniature ventilator may be relayed to an intermediate pneumatic device such as the Air Shields Bellows ventimeter as shown in Figure 7. Although anaesthetic gas, oxygen, and halothane requirements may be less in this system with the soda-lime canister in circuit, it is necessary to provide a separate source of compressed oxygen or air for motive power. Hence the presence of an accessory flowmeter to provide pneumatic energy to the reservoir bag as well as appropriate minute volume measurement. Notwithstanding the economical aspect of such a system, we believe that the real advantage lies in conservation of water vapour due to the presence of soda-lime in a semi-closed partial-rebreathing system. ${ }^{7,8,9}$

The introduction of a to-and-fro canister directly between patient and miniature ventilator as a means of solving humidity problems would obviously introduce the same objection concerning dead space as that represented in Figure 5, and must be condemned.

To partially circumvent the undesirable effects of dry gases on the respiratory mucosa when the non-rebreathing interrupted circle system is used for anaesthesia of long duration, a heat and moisture exchanger ${ }^{10}$ may be inserted between the endotracheal tube and the $\mathrm{Y}$ unidirectional valve.

\section{Discussion}

Although miniature ventilators may not combine all the desirable features of the more elaborate and versatile conventional machines of much larger size, they nevertheless deserve our attention.

For various reasons, space in the operating room is becoming more and more restricted. In order to provide accessibility to the immediate surgical problem, it has become almost a necessity to eradicate unnecessary clutter. ${ }^{11}$ Space-capsule technology and methodology should inspire us in establishing suitable environmental working conditions in the operating room. Miniaturization is a commendable solution to the problem wherever applicable.

Miniature ventilators are not foolproof and they must be monitored with sustained vigilance. Since it appears to us that magnetic valves work better when 
dry, we recommend thorough and frequent cleaning of all functional surfaces with ether. Transient pressure transmitted to the lungs by a retractor impinging on the diaphragm will create an opposing pressure sufficient to cause arrest of the magnetic valve in the inspiratory position. Needless to say, should uninterrupted inflation of the lungs occur, pressure should be released instantly. This is accomplished by the safety relief valve or by opening either side of the circle.

Under normal circumstances, the regularity of operation of the magnetic valve signifies absence of malfunction. Therefore should the sound of the magnetic valve be masked by a higher level noise source, such as that produced by a surgical air drill, great visual caution should be exercised.

It has not been our intention either to compare or individually evaluate the ventilators used in our present study. Under close supervision, we find that they all work satisfactorily provided reservoir bags of appropriate compliance are used.

Following numerous preliminary trials, the Minivent was used in a paediatric transplant procedure and performed faithfully and reliably for sixteen consecutive hours.

The British tapers on the ventilators did not prevent their adaptation to all types of anaesthetic machines and to the various circuits herein described. Connections from available material or machined adaptors were used.

\section{ConClUSIONS}

It is hoped that innovations insuring foolproof functioning will soon be incorporated in miniature ventilators without necessarily increasing their pocket-size convenience. In the interval, we strongly urge responsible, alert anaesthetists to become familiar with these space saving devices.

\section{SUMMARY}

A brief description of the mechanical principles involved in three modern miniature ventilators is presented.

Anaesthetic circuits as recommended in the past are illustrated and their shortcomings expressed in the light of our experience.

An interrupted non-rebreathing circle system adaptation is described.

Arterial $\mathrm{Pa}_{\mathrm{CO}_{2}}$ observations are presented and interpreted.

Dangerous pitfalls to be avoided in setting up circuits are described.

Explanations for clogged magnetic valves in the inspiratory mode are presented and prophylactic and corrective measures recommended to avoid overinflation of the lungs.

The economic aspects of ventilator miniaturization are discussed with regard to initial low cost and total anaesthetic mixture output.

A semi-closed partial-rebreathing system is described but not necessarily recommended because "overloading" with intermediate pneumatic accessories appears to interfere with the fidelity of operation of miniature ventilators. 


\section{RÉSUMÉ}

Après une courte introduction sur l'histoire et sur les principes mécaniques concernant les ventilateurs miniaturisés, les auteurs décrivent un nouveau type d'adaptation pour ces appareils: le système circulaire interrompu ou sans réinhalation des gaz expirés.

L'étude de la $\mathrm{PaCO}_{2}$ dans un groupe de patients a été faite et confirme l'efficacité de ce nouveau système d'adaptation des respirateurs miniaturisés.

Les circuits ou systèmes anesthésiques à proscrire sont mentionnés et les causes, la correction et la prophylaxie d'accidents possibles comme l'hyperinsufflation des poumons, sont analysées.

Tout en insistant sur les avantages de la "miniaturisation" des appareils employés en salle d'opération, et en passant par l'aspect économique, les auteurs montrent la possibilité d'appliquer de tels ventilateurs en circuit semi-fermé sans toutefois recommander l'emploi de cette dernière possibilité.

\section{REFERENCES}

1. Cohen, A. D. The Minivent Respirator, Anaesthesia. 21:563 (1966).

2. Collis, J. M.; Bethune, D. W.; \& Tobias, M. H. Miniature Ventilators, An assessment. Anaesthesia. 24: 81 (1969).

3. Carden, E. The Microvent Ventilator. Anaesthesia. 24: 90 (1969).

4. Wright, B. M. A Respiratory Anemometer. J. Physiol. Lond. 127: 25 (1955).

5. Carden, E. A Simple Portable Ventilator for Emergency Resuscitation. Anaesthesiology. 32: 269 (1970).

6. Mushrn, W. W. et al. Automatic Ventilation of the Lungs, 2nd ed. (Oxford and Edinburgh; Blackwell Scientific Publication (1969).

7. Dery, R.; Pelletier, J.; Jacques, A.; Clavet, M.; \& Houde, J. J. Humidity in Anaesthesiology: 1. A Modified Dew-Point Hygrometer. Canad. Anaesth. Soc. J. 14: 104 (1967).

8. Defy, H.; Pelletier, J.; Jacques, A.; Claver, M., \& Houde, J. J. Humidity in Anaesthesiology: Ir. Evolution of Heat and Moisture in Large Carbon Dioxide Absorbers. Canad. Anaesth. Soc. J. 14: 205 (1967).

9. Dery, H.; Pelletuer, J.; Jacques, A.; Clavet, M.; \& Houde, J. J. Humidity in Anaesthesiology: m. Heat and Moisture Patterns in the Respiratory Tract During Anaesthesia with the Semi-Closed System. Canad. Anaesth. Soc. J. 14: 287 (1967).

10. Chamney, A. R. Humidification Requirements and Techniques Including a Review of the Performance of Equipment in Current Use. Anaesthesia. 24: 602 (1969).

11. Bhunet, J. L. Conception Nouvelle de l'Aménagement d'une Salle d'Opération. Canad. Anaesth. Soc. J. 12: 161 (1965). 